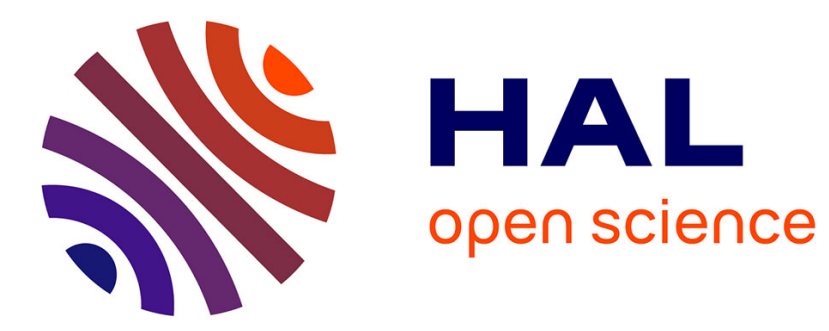

\title{
9H-Quinolino[3,2,1-k]phenothiazine: A New Electron-Rich Fragment for Organic Electronics
}

Cyril Poriel, Joëlle Rault-Berthelot, Sébastien Thiery, Cassandre Quinton, Olivier Jeannin, Urelle Biapo, Denis Tondelier, Bernard Geffroy

\section{- To cite this version:}

Cyril Poriel, Joëlle Rault-Berthelot, Sébastien Thiery, Cassandre Quinton, Olivier Jeannin, et al.. 9HQuinolino[3,2,1-k]phenothiazine: A New Electron-Rich Fragment for Organic Electronics. Chemistry - A European Journal, 2016, 22 (50), pp.17930 - 17935. 10.1002/chem.201603659 . cea-01414714

\author{
HAL Id: cea-01414714 \\ https://hal-cea.archives-ouvertes.fr/cea-01414714
}

Submitted on 12 Jul 2017

HAL is a multi-disciplinary open access archive for the deposit and dissemination of scientific research documents, whether they are published or not. The documents may come from teaching and research institutions in France or abroad, or from public or private research centers.
L'archive ouverte pluridisciplinaire HAL, est destinée au dépôt et à la diffusion de documents scientifiques de niveau recherche, publiés ou non, émanant des établissements d'enseignement et de recherche français ou étrangers, des laboratoires publics ou privés. 


\title{
9H-Quinolino[3,2,1-k]phenothiazine: A new electron-rich fragment for organic electronics
}

\author{
Cyril Poriel, 'Joëlle Rault-Berthelot, "Sébastien Thiery, Cassandre Quinton, Olivier Jeannin, Urelle Biapo, \\ Denis Tondelier, Bernard Geffroy
}

Since the last 30 years, the fantastic emergence of organic electronics is assignable to the design, the synthesis and the study of thousands of organic semi-conductors (OSCs) with specific properties fitting with the different electronic devices. ${ }^{[1-4]}$ Since the discovery of the 'host/guest concept' in Phosphorescent Organic Light Emitting Diodes (PhOLEDs), ${ }^{[5]}$ the design of OSCs usable as host materials for blue emitting phosphors has been an intense research field worldwide. ${ }^{[4]}$ In addition to its high thermal/morphological stability and its high triplet energy $\left(\mathrm{E}_{\mathrm{T}}\right)$, an ideal host should also possess a bipolar character with HOMO and LUMO energy levels adapted to the Fermi levels of the electrodes. ${ }^{[6-9]}$ However, there is a certain antinomy between a high $\mathrm{E}_{\mathrm{T}}$ (essential to insure efficient energy transfers) and a short HOMO/LUMO gap (essential to insure efficient charge injection) and the best trade-off should be found for the ideal host. If the nature of the linkage ${ }^{[10]}$ between the electron rich and the electron poor units is of key importance to control the $\mathrm{E}_{\mathrm{T}}$ as well as the $\mathrm{HOMO} / \mathrm{LUMO}$ gap, their intrinsic properties remain nevertheless the most important characteristics. In this context, the widely known electron rich carbazole fragment has led to impressive breakthroughs and is nowadays an important building block in organic electronics. ${ }^{[11,12]}$ Around the molecular structure of carbazole, many other carbazole-like fragments have been developed in the recent years sometimes surpassing the performance of the carbazole fragment in electronics. Thus, indolocarbazole (IC) ${ }^{[13]}$ phenylacridine $(\mathrm{PA})^{[14-16]}$ and more recently indoloacridine (IA) ${ }^{[17]}$ are nowadays key building blocks, widely used in all organic electronic devices.
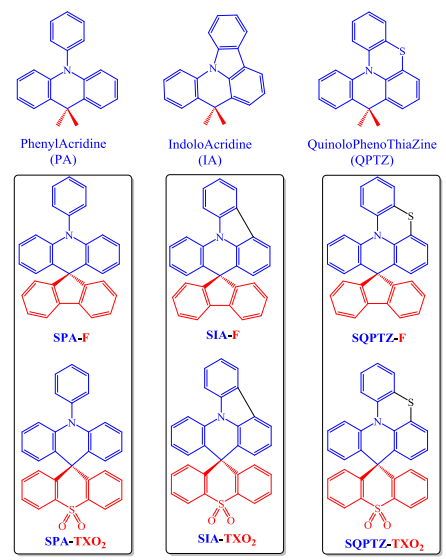

Chart 1: Phenylacridine (PA, left), ${ }^{[14,18]}$ indoloacridine (IA, middle) ${ }^{[17]}$ and quinolophenothiazine (QPTZ, right) based semi-conductors

As the future of organic electronics strongly relies on the

[*] Dr C. Poriel ${ }^{*}$, Dr J. Rault-Berthelot, ${ }^{*}$ Dr S. Thiery, Dr C. Quinton, $\mathrm{Dr}$ O. Jeannin UMR CNRS 6226-ISCR-Université de Rennes 135042 Rennes cedex-France.

E-mail:cyril.poriel@univ-rennes1.fr,joelle.rault@univ-rennes1.fr Dr D. Tondelier, U. Biapo, B. Geffroy

LPICM, CNRS, Ecole Polytechnique, Université Paris Saclay, 91128 Palaiseau, France

B. Geffroy

LICSEN, NIMBE, CEA, CNRS, Université Paris-Saclay, CEA Saclay 91191 Gif-sur-Yvette Cedex, France

[**] We thank the CDIFX and CRMPO (Rennes), GENCI (France) and CINES (Montpellier, c2016085032), the ISN (Gif Sur Yvette) and the ANR ( ${ }^{\circ} 11-B S 07-020-01$ and 14-CE05-0024) for financial support discovery of novel elementary molecular fragments, such as for example the new bithiophenesulfonamide building block recently reported by Marks, Facchetti et al, ${ }^{[19]}$ we wish to report herein a new promising electron rich core, namely the quinolophenothiazine (QPTZ). The QPTZ unit can be seen as a two ortho-bridged triphenylamine or as a pentacyclic fused ring amine. The QPTZ fragment is hence an IA core in which a sulphur atom has been incorporated within the biphenyl linkage. This sulphur atom is expected to have a major role in the electronic properties with the raising of the HOMO energy level and of the spin-orbit coupling. Thus, this molecular fragment, described more than 35 years ago, ${ }^{[20]}$ is nevertheless to the best of our knowledge, almost absent from literature with only one example reported without any device application. ${ }^{[21]}$ Herein, the potential of the QPTZ fragment has been evaluated through the synthesis of two spiro-configured dyes, Spiroquinolophenothiazine-Fluorene (SQPTZ-F) and Spiroquinolophenothiazine-dioxothioxanthene (SQPTZ-TXO $\left.\mathbf{O}_{2}\right)$ possessing a D-Spiro-A design (Scheme 1). ${ }^{[14-16]}$ These semiconductors have been studied in detail, incorporated as host materials in blue PhOLEDs and compared to their structurally related parents possessing a PA $\left(\mathbf{S P A}-\mathbf{T X O}_{2}{ }^{[15]} / \mathbf{S P A}-\mathbf{F}{ }^{[18]}\right.$ Chart 1-left) or an IA core (SIA-TXO ${ }_{2} / \mathbf{S I A - F},{ }^{[17]}$ Chart 1-middle) previously reported in literature. It turns out that with a combination of a moderate triplet energy and a high HOMO energy level, the QPTZ fragment appears to lead to strongly more efficient blue PhOLEDs than those reported with the IA and PA fragments. This first electronic application displays the fantastic potential of this fragment in organic electronics.

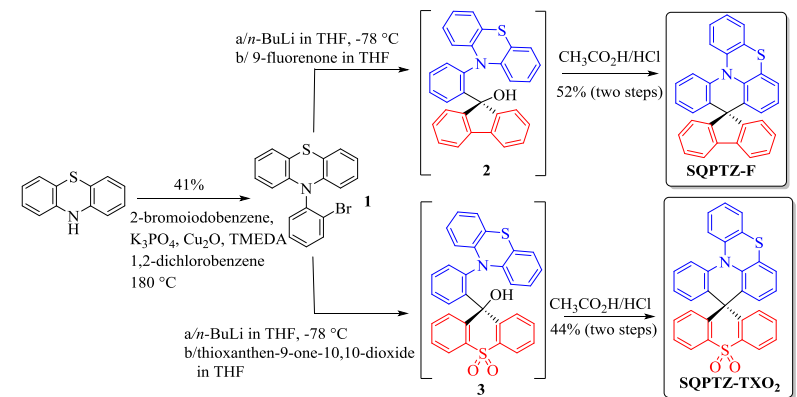

Scheme 1: Synthesis of SQPTZ-F and SQPTZ-TXO

SQPTZ-F and SQPTZ-TXO ${ }_{2}$ were readily obtained through a short and highly efficient synthetic approach by coupling the halogeno-aryl 10-(2-bromophenyl)-10H-phenothiazine $\mathbf{1}$, obtained from the copper catalysed Goldberg coupling of phenothiazine and 2-bromoiodobenzene (Scheme 1), with either 9-fluorenone (for SQPTZ-F) or 9H-thioxanthen-9-one-10,10dioxide (for SQPTZ-TXO $\mathbf{2}_{2}$ ). The corresponding fluorenol 2 and thioxanthenol $\mathbf{3}$ respectively obtained were not isolated and were involved in an intramolecular electrophilic substitution to provide the two targets SQPTZ-TXO $\mathbf{O}_{2}$ and SQPTZ-F with good yields. These short and efficient synthetic approaches allow a gram-scale preparation, key feature for electronic applications.

X-ray diffraction data (Figure 1) show that SQPTZ-F crystallizes in a monoclinic system, $P 2_{1} / \mathrm{a}$, revealing an asymmetric unit containing two molecules (Mol1/Mol2, see Fig. S1-S4/S7-S10 in SI) whereas SQPTZ-TXO $\mathbf{O}_{2}$ crystallizes in a triclinic system $P-1$ with also two molecules (Mol1/Mol2, see Fig. S13-S16/S19-S22 in SI). A rough value of the molecular radius of each molecule 
(approximately obtained by the distance from the spiro carbon atom to the farthest carbon atom) has been evaluated at $6.7 \AA$ for SQPTZ-F and at 6.8-6.9 $\AA$ for SQPTZ-TXO 2 . For both molecules, this radius is imposed by the QPTZ unit, which is larger than the other aromatic units $\left(\mathrm{F}\right.$ or $\left.\mathrm{TXO}_{2}\right)$. These radii (involved in the Lippert-Mataga formalism used to determine the polarity of the excited states, Figure 3D) are smaller than those reported for structurally analogues SIA-TXO $\mathbf{O}_{2} / \mathbf{S I A - F}$ (6.95 to $7.02 \AA)^{[17]}$ and SPA-TXO 2 /SPA-F $(7.14 \AA) .{ }^{[14]}$ As the molecular radius is governed by the QPTZ unit, its decrease comes from a more intense deformation of the QPTZ unit compared to that of its structurally related analogues, IA and PA fragments, which are not deformed at all. Indeed, the significant deformation of the QPTZ core mainly finds its origin in the deformation of the phenothiazine unit (deformation angle from $37.4^{\circ}$ to $46.9^{\circ}$ ) and to a lesser extent in that of the acridine units (deformation angle between 15.1 and $32.9^{\circ}$ ). This strong deformation of the QPTZ core is a key feature to maintain a high $\mathrm{E}_{\mathrm{T}}$ (see below). It should be stressed that these important structural features lead to very short intramolecular $\mathrm{C} / \mathrm{C}$ contacts (shorter than the sum of their Van der Walls radii, see Fig. S5, S11, S17 and S23 in SI). A very short intramolecular $\mathrm{C} / \mathrm{C}$ distance of ca $3.0 \AA$ is especially detected between the two carbons in $\beta$ position of the nitrogen atom highlighting the strong steric congestion between the phenothiazine and the acridine backbones.

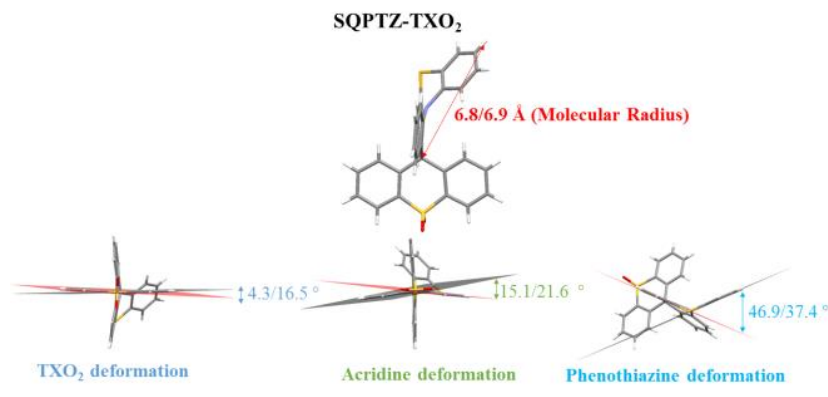

SQPTZ-F

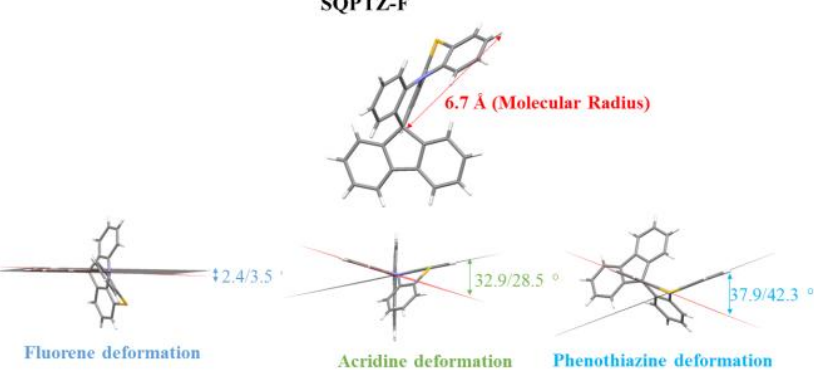

Figure 1. Molecular structures of SQPTZ-TXO (bottom) exemplified by one molecule ( $\mathrm{Mol} \mathrm{l}$ ) with extreme values of the different parameters for the 2 molecules present in the asymmetric unit

The electron rich character of the QPTZ fragment is the most important feature and has been investigated by cyclic voltammetry (Figure 2). In oxidation, the two compounds remarkably present two reversible single electron oxidation processes with peak potentials $\mathrm{E}^{1} / \mathrm{E}^{2}$ ( $v s$ SCE) recorded at 0.89/1.61 V for SQPTZ-F and at 1.0/1.64 V for SQPTZ-TXO $\mathbf{S}_{2}$. As $\mathrm{TXO}_{2}$ and $\mathrm{F}$ moieties are oxidised through irreversible processes, these two oxidation waves have been assigned to two single electron transfers involving the QPTZ core. Thus, the first oxidation of the QPTZ fragment remarkably occurs at a less anodic potential than that of the PA $\left(\mathrm{E}^{1}>1.11 \mathrm{~V}\right.$ in SPA$\left.\mathbf{T X O}_{2}\right)^{[17]}$ and that of the IA core $\left(\mathrm{E}^{1}=1.33 \mathrm{~V}\right.$ for SIA-TXO $\mathbf{S}_{\mathbf{2}}$ and $1.19 \mathrm{~V}$ for SIA-F). ${ }^{[14]}$ This strong electron rich character finds hence its origin in the electron donating behaviour of the intracyclic sulphur atom, which fully drives the HOMO energy level of these dyes (Figure 4). Another important feature deserves to be stressed out. Indeed, the reversibility of the two first oxidation waves clearly shows the efficient delocalization of the charges within the QPTZ core, which is not the case for the structurally analogues based on the IA or on the PA core (Figure 2-right). ${ }^{[14,17]}$ Thus, the sulphur atom has a significant impact on the electrochemical properties not only in terms of potential but also in the stability of the cationic species. From the onset potential pointed at $0.9 \mathrm{~V}$, we determined the $\mathrm{HOMO}$ energy level of SQPTZ-TXO $\mathbf{O}_{2}$ at $-5.3 \mathrm{eV}$, significantly higher than that of SPA-TXO $2(-5.42 \mathrm{eV})$ and SIA-TXO $(-5.61 \mathrm{eV})$. Similarly, the HOMO energy level of SQPTZ-F $(-5.16 \mathrm{eV})$ is more than 0.3 $\mathrm{eV}$ higher than that of SIA-F $(-5.48 \mathrm{eV})$ confirming the strong electron-rich nature of the QPTZ fragment. ${ }^{[14]}$ One can also note that the HOMO energy level of SQPTZ-F is higher than that of SQPTZ-TXO ${ }_{2}$, translating the non-negligible influence of the acceptor unit on the HOMO level via the spiro bridge. Thus, the HOMO energy levels of QPTZ based molecules are high and should favour the hole injection within an electronic device.
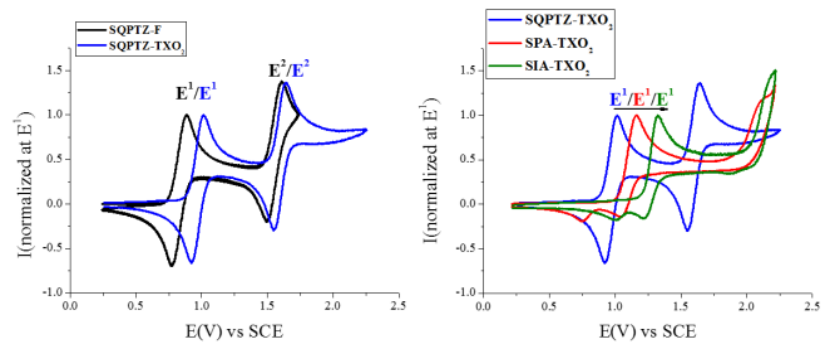

Figure 2. Cyclic voltammetry $\left(\mathrm{CH}_{2} \mathrm{Cl}_{2}+\mathrm{Bu}_{4} \mathrm{NPF}_{6} 0.2 \mathrm{M}\right.$, sweep-rate 100

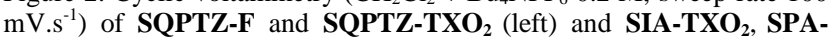
$\mathbf{T X O}_{2}$ and SQPTZ-TXO $\mathbf{S}_{2}$ (right).

In reduction, neither SQPTZ-F nor SQPTZ-TXO ${ }_{2}$ present any distinguishable reduction wave before the accessible limit of the present electrolytic solution (see Fig. S33 in SI). We determined their LUMO energy levels from the onset potential of their reduction at -1.85 and $-2.06 \mathrm{eV}$ for SQPTZ-F and SQPTZ$\mathbf{T X O}_{2}$, highlighting the stronger electron-poor character of $\mathrm{TXO}_{2}$ compared to that of $\mathrm{F}$ in accordance with the above mentioned results on HOMO energies. The electrochemical gaps $\left(\Delta \mathrm{E}^{\mathrm{el}}\right)$ were found to be $3.31 \mathrm{eV}$ for SQPTZ-F and $3.24 \mathrm{eV}$ for SQPTZ$\mathbf{T X O}_{2}$. Thus, SQPTZ-TXO $\mathbf{2}_{2}$ possesses a $\Delta \mathrm{E}^{\mathrm{el}}$ significantly contracted by $0.2 / 0.3 \mathrm{eV}$ compared to that of the PA and IA counterparts $\left(\Delta \mathrm{E}^{\mathrm{el}} \mathbf{S P A}-\mathbf{T X O}_{2}=3.43 \mathrm{eV}, \Delta \mathrm{E}^{\mathrm{el}} \mathbf{S I A}-\mathbf{T X O} \mathbf{O}_{2}=3.56\right.$ $\mathrm{eV})$ due to its high HOMO energy level. As the same gap contraction is detected between SIA-F and SQPTZ-F (3.60 vs $3.31 \mathrm{eV}$ resp.), this clearly highlights the strong impact of the QPTZ fragment to contract the gap, independently of the spiroconnected unit. Geometry optimization of the two compounds was performed using density functional theory (DFT, B3LYP/6$31 \mathrm{G}(\mathrm{d}))$. The HOMO and LUMO levels follow the same tendencies than those obtained by electrochemical studies with notably a higher HOMO energy level for SQPTZ-F $(-5.03 \mathrm{eV})$ than for SQPTZ-TXO $(-5.30 \mathrm{eV})$. The HOMO levels are spread on the QPTZ fragment (Figure 4), confirming a first electron transfer from this core. The calculated LUMO levels are respectively lying at -0.92 and $-1.17 \mathrm{eV}$ for SQPTZ-F and SQPTZ-TXO $\mathrm{O}_{2}$ and are spread out on the fluorene of SQPTZ-F

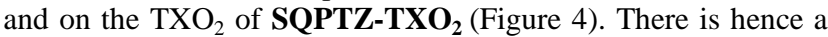
complete electronic separation between the HOMO and the LUMO, which will have important repercussions on the photophysical processes (see below). This orbital separation is a key point to gather within a single dye the HOMO/LUMO energy levels of the constituting building blocks, a short $\pi$-conjugation pathway and a high $\mathrm{E}_{\mathrm{T}}$.

Absorption spectra of SPQTZ-TXO $\mathbf{O}_{2}$ and SQPTZ-F are presented in Figure 3A. SQPTZ-F presents an UV-vis spectrum with maxima recorded at 262, 296 and 308 similar to that of its 
building unit fluorene $(265,290,301 \mathrm{~nm})$ at the exception of the long tail observed between 320 and $360 \mathrm{~nm}$. In the light of TDDFT, the main absorption band centred at $308 \mathrm{~nm}$ is assigned to a transition with two contributions (HOMO/LUMO+4 and $\mathrm{HOMO} / \mathrm{LUMO}+5$, $\mathrm{f}=0.117$, see Fig. S37 in SI) implying only the QPTZ fragment, the one at $296 \mathrm{~nm}$ is attributed to fluorenefluorene transition (HOMO-1/LUMO, $\mathrm{f}=0.067$ ), and the large high energy band at $262 \mathrm{~nm}$ to phenyl-phenyl transitions. More importantly, the low energy tail is noticeably large due to the flexibility induced by the presence of the sulphur atom within the QPTZ fragment and is assigned to $\mathrm{HOMO} / \mathrm{LUMO}+1$ and $\mathrm{HOMO} / \mathrm{LUMO}+2$ transitions (Figure 4-left). Indeed, the calculated absorption spectrum shows that the first excited state corresponds to an HOMO-LUMO transition but with a very weak oscillator strength $(\mathrm{f}=0.0002)$, not detectable experimentally. This is a crucial point in the D-spiro-A design, which finds its origin in the spatial separation of HOMO and LUMO levels (HOMO delocalized on the QPTZ core and LUMO on the fluorene core) leading to through-space forbidden transitions. Oppositely, the HOMO/LUMO+1 and HOMO/LUMO+2 transitions possess oscillator strengths of ca 0.02 , being ca 100 times more probable than the HOMO/LUMO transition (Figure 4-left). These transitions involve almost exclusively the QPTZ core which hence governs the optical gap $\Delta \mathrm{E}^{\text {opt }}$ of SQPTZ-F (ca 3.3/3.4 eV). Despite an almost identical $\Delta \mathrm{E}^{\mathrm{opt}}$, the absorption spectrum of SPQTZ-TXO ${ }_{2}$ is slightly different in the low energy region with a broader tail. As observed for SQPTZ-F, the HOMO/LUMO transition of SPQTZ-TXO 2 possesses a very weak oscillator strength ( $\mathrm{f}=0.003$, Figure 4-right) due to the spatial separation of HOMO (centred on QPTZ) and LUMO (centred on $\mathrm{TXO}_{2}$ ) and is not experimentally observed. Thus, the main low-energy transition is an HOMO/LUMO+1 transition ( $\mathrm{f}=$ 0.042 , see Fig. S39 in SI). There is nevertheless a significant difference between SPQTZ-F and SPQTZ-TXO, which is linked to the different localization of the LUMO+1 orbital: on the QPTZ core for the former and on the $\mathrm{TXO}_{2}$ core for the latter. This difference confers to the HOMO/LUMO+1 transition of SPQTZ-TXO ${ }_{2}$ a notable charge transfer character, which is not the case for SPQTZ-F (see solvatochromic experiments Figure 3D).
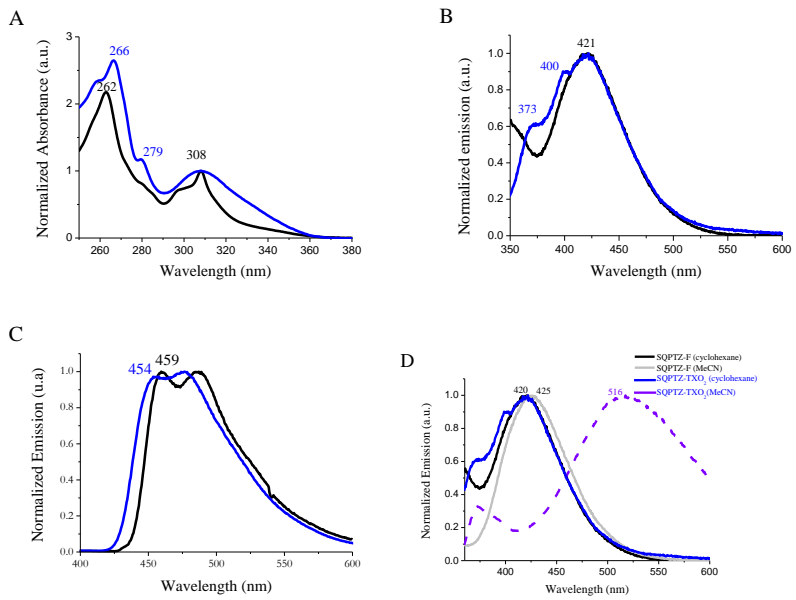

Figure 3. Optical properties of SQPTZ-F (black line) and SQPTZ-TXO (blue line); A: UV-vis absorption spectra (cyclohexane), B: Emission spectra (cyclohexane) at $\mathrm{rt}$ under argon $\left(\lambda_{\text {exc }}=330 \mathrm{~nm}\right), \mathrm{C}$ : Emission spectra at $77 \mathrm{~K}\left(2-\mathrm{MeTHF}, \lambda_{\mathrm{exc}}=315 \mathrm{~nm}\right)$. D: Emission spectra in cyclohexane and acetonitrile.

SPQTZ-TXO $_{2}$ and SQPTZ-F display almost no fluorescence and the emission spectra were recorded in absence of oxygen (under argon, Figure 3B). Thus, the emission of SQPTZ-F and that of SQPTZ-TXO $\mathbf{O}_{2}$ appear very similar with a main large and unresolved band at $421 \mathrm{~nm}$. The quantum yields (QY), measured in presence of oxygen, appear very low (QY $<0.05$ for both). Thus, QPTZ fragment, due to the insertion of the intracyclic sulphur atom, is very weakly fluorescent in opposition to the IA core, which is highly fluorescent (QY 0.4). ${ }^{[17]}$ This feature can be assigned to internal heavy atom effects as recently shown for phenothiazinium dyes and highlights the significant impact of the sulphur atom on the electronic properties of the QPTZ fragment. ${ }^{[22]}$ Solvatochromic experiments allow a deeper understanding of the photophysical properties through the determination of the polarity of the excited states (Figure 3, bottom-right). Indeed, the emission maximum of SQPTZ-F in polar $\mathrm{MeCN}$ is recorded at $425 \mathrm{~nm}$, being only very weakly shifted by $4 \mathrm{~nm}$, compared to that in apolar cyclohexane (421 $\mathrm{nm})$, in accordance with a transition occurring with only one fragment involved, namely QPTZ. SQPTZ-TXO $\mathbf{O}_{2}$ displays a very different behaviour with an impressive red shift of $98 \mathrm{~nm}$ between cyclohexane $(421 \mathrm{~nm})$ and $\mathrm{MeCN}(516 \mathrm{~nm})$ highlighting a strong photoinduced Intramolecular Charge Transfer (ICT) character due to the different localization of the HOMO and LUMO+1 levels. $\Delta \mu$ values of $6.05 \mathrm{D}$ and $21.51 \mathrm{D}$ have been evaluated using the Lippert-Mataga formalism (the dipole moments at the ground state obtained through DFT calculations were: 1.6 and 5.1 D for SQPTZ-F and SQPTZ-TXO $\mathbf{S}_{2}$, see Fig. 27-29 in SI), translating the different polarity of the two dyes at the excited state $(\mu *=7.5$ and $26.6 \mathrm{D}$ resp.). Thus, the strong solvatochromic effect and the corresponding high $\mu *$ observed for SQPTZ-TXO ${ }_{2}$ are indicative of a significant photoinduced ICT whereas the negligible solvatochromic effect and the corresponding low $\mu *$ observed for SQPTZ-F are indicative of a very weak photoinduced ICT. Thus, the acceptor unit can drastically change the electronic properties of QPTZ based dyes.

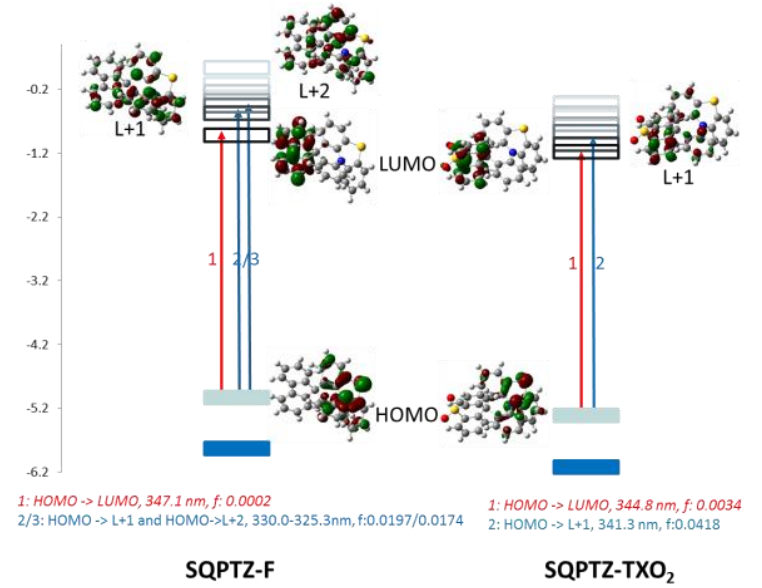

Figure 4. The first calculated electronic transitions of SPQTZ-F (Left)

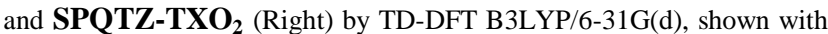
an isovalue of $0.04\left[\mathrm{e} \mathrm{bohr}^{-3}\right]^{1 / 2}$.

The phosphorescent spectra (Figure 3C), recorded at 77K, appear large and weakly structured and contrarily to the fluorescence spectra, are relatively intense. As the fluorescence of the two molecules is low, the intersystem crossing (ISC) between $\mathrm{S}_{1}$ and $\mathrm{T}_{1}$ is fast and the phosphorescence contribution at $77 \mathrm{~K}$ is very intense. This is a remarkable characteristic of the QPTZ fragment, which results from the incorporation of the sulphur atom which enhances the ISC by vibronic spin-orbit coupling. ${ }^{[22]}$ The transition of highest energy presents a maximum at $459 \mathrm{~nm}$ for SQPTZ-F and $454 \mathrm{~nm}$ for SQPTZ-TXO $\mathbf{2}_{2}$ giving respective triplet energy $\mathrm{E}_{\mathrm{T}}$ of 2.70 and $2.73 \mathrm{eV}$. QPTZ based compounds possess hence an $\mathrm{E}_{\mathrm{T}}$ of ca $2.7 \mathrm{eV}$, smaller than those of PA (3.08 $\mathrm{eV}$ for SPA-TXO $\mathbf{S}_{2}$ and $3.02 \mathrm{eV}$ for SPA-F) and IA analogues $\left(2.93 \mathrm{eV}\right.$ SIA-TXO $\mathbf{2}_{2}$ and $2.87 \mathrm{eV}$ for SIA-F) indicating a different localization of the triplet exciton in IA, PA and QPTZ 
based molecules. In summary, thanks to the QPTZ fragment, the two dyes possess an HOMO/LUMO gap relatively small as well as an $\mathrm{E}_{\mathrm{T}}$ high enough to be used with the blue FIrpic phosphor $\left(\mathrm{E}_{\mathrm{T}}=2.62 \mathrm{eV}^{[23]}\right)$. This combination appears appealing for the future design of host materials based on this fragment.

The potential of the QPTZ fragment in electronics has been finally evaluated using SQPTZ-F as host in a blue PhOLED (10\% FIrpic). The performance of these devices has been compared to those of structurally related SIA and SPA analogues with exactly the same device architecture. Indeed, in order to accurately compare the performance of the hosts, the device architecture should be strictly identical (see PhOLED architecture in SI). Thus, SQPTZ-F displays a very high EQE of $15.8 \%$ at $\mathrm{J}=10 \mathrm{~mA} / \mathrm{cm}^{-2}$ with corresponding Current Efficiency (CE) of $32.8 \mathrm{~cd} . \mathrm{A}^{-1}$ and Power Efficiency (PE) of $21.7 \mathrm{~lm} . \mathrm{W}^{-1}$ (see Fig. $\mathrm{S} 40$ in SI). These performances are ca 50\% higher than those recorded with the IA counterpart SIA-F (EQE of $10.7 \%$ at $\mathrm{J}=10$ mA.cm ${ }^{-2}$ with corresponding CE of $24.2 \mathrm{~cd} . \mathrm{A}^{-1}$ and PE of 13.3 $1 \mathrm{~m} . \mathrm{W}^{-1}$ ) (see Fig. S42 in SI). In addition, the turn on voltage $\mathrm{V}_{\text {on }}$ (at $1 \mathrm{~cd}^{\mathrm{c}} \mathrm{m}^{-2}$ ) of SQPTZ-F based device appears to be very low, 2.7 V, for a blue PhOLED and significantly lower than that of SIA-F recorded at $3.5 \mathrm{~V}$. This feature clearly translates a better charge injection within the SQPTZ-F/FIrpic emitting layer than within the SIA-F/FIrpic one. Similarly, SQPTZ-TXO ${ }_{2}$ emits light at a low voltage of $2.8 \mathrm{~V}$ and displays a very high EQE of $15.8 \%\left(10 \mathrm{~mA} / \mathrm{cm}^{-2}\right)$ with corresponding $\mathrm{CE}$ and $\mathrm{PE}$ of 33.1 cd. $\mathrm{A}^{-1}$ and $17.6 \mathrm{~lm} . \mathrm{W}^{-1}$ (see Fig. S41 in SI), clearly highlighting that these very high performances are induced by the QPTZ fragment. The electroluminescent spectra of all devices (see Fig. S40-41 in SI) are identical, exclusively showing the emission of the blue dopant at 472 and $496 \mathrm{~nm}$ close to the photoluminescence of pure FIrpic $(468 / 495 \mathrm{~nm}$ in solution in $\mathrm{CH}_{2} \mathrm{Cl}_{2}$ ), indicating efficient energy transfers. ${ }^{[23]}$ It is also important to mention that SQPTZ-F and SQPTZ-TXO $\mathbf{O}_{\mathbf{2}}$ displays a better performance and a lower turn on voltage than structurally related IA and PA compounds reported in literature. Thus, SIA$\mathbf{T X O}_{2}$ (EQE of $12.7 \%$ at $10 \mathrm{~mA} \cdot \mathrm{cm}^{-2}$ with corresponding CE of 27.7 cd. $\mathrm{A}^{-1}$, PE of $14.5 \mathrm{~lm} . \mathrm{W}^{-1}$ and a $\mathrm{V}_{\text {on }}$ of $\left.2.9 \mathrm{~V}\right)^{[17]}$ and SPATXO $_{2}$ (EQE of $11.4 \%$ at $10 \mathrm{~mA} . \mathrm{cm}^{-2}$ with CE of $28.4 \mathrm{~cd}^{-\mathrm{A}^{-1}}$, LE of $14.4 \mathrm{~lm} . \mathrm{W}^{-1}$ and a $\mathrm{V}_{\text {on }}$ of $\left.2.9 \mathrm{~V}\right)^{[15]}$ both display a lower performance and a higher $\mathrm{V}_{\text {on }}$ than that exposed above. Thus, switching from IA or PA core to QPTZ allows a strong EQE increase as well as a decrease of the $\mathrm{V}_{\text {on }}$. Some recent universal hosts based on the indolocarbazole backbone, namely diphenylindolocarbazole $(\mathrm{EQE}=10.4 \%)$ and phenylpyridineindolocarbazole $(\mathrm{EQE}=13.4 \%)^{[13]}$ also display lower performance for FIrpic based devices than those reported herein, indicating the strong potential of the QPTZ core in electronics.

In summary, this work reports the first example of a new molecular fragment, namely QPTZ, used in electronics. The QPTZ fragment can be easily synthesized, presents a high HOMO level, $-5.2 / 5.3 \mathrm{eV}$ and a moderate $\mathrm{E}_{\mathrm{T}}$ value of ca $2.7 \mathrm{eV}$. This combination leads to high-efficiency blue PhOLEDs displaying higher performance (increase by 50\%) than those reported with the PA and IA analogues. This preliminary result highlights the potential of this fragment in the field of PhOLEDs. We believe that the future development of QPTZ based materials is appealing for other organic devices and can advance the field of organic semi-conducting materials.

\section{Acknowledgment:}

Keywords: Quinolophenothiazine . PhOLED organic semiconductors· spiro compounds

[1]M. Gsänger, D. Bialas, L. Huang, M. Stolte, F. Würthner, Adv. Mater. 2016, 28, 3615 .

[2]S.-L. Suraru, F. Würthner, Angew. Chem. Int. Ed. 2014, 53, 7428

[3]C. Wang, H. Dong, W. Hu, Y. Liu, D. Zhu, Chem. Rev. 2012, 112, 2208 .
[4]K. S. Yook, J. Y Lee, Adv, Mater 2012, 24, 3169.

[5]M. A. Baldo, D. F. O'Brien, Y. You, A. Shoustikov, S. Sibley, M. E. Thompson, S. R. Forrest, Nature 1998, 395, 151.

[6]C. Fan, L. Zhu, T. Liu, B. Jiang, D. Ma, J. Qin, C. Yang, Angew. Chem. Int. Ed. 2014, 53, 2147.

[7]C. Han, Z. Zhang, H. Xu, G.-H. Xie, R. Chen, Y. Zhao, W. Huang, Angew. Chem. Int. Ed. 2012, 124, 10251.

[8]S. Thiery, D. Tondelier, B. Geffroy, E. Jacques, M. Robin, R. Métivier, O. Jeannin, J. Rault-Berthelot, C. Poriel, Org. Lett. 2015, 17, 4682.

[9]J.-J. Huang, Y.-H. Hung, P.-L. Ting, Y.-N. Tsai, H.-J. Gao, T.-L. Chiu, J.-H. Lee, C.-L. Chen, P.-T. Chou, M.-k. Leung, Org. Lett. 2016, 18, 672. [10] a. M. Romain, S. Thiery, A. Shirinskaya, C. Declairieux, D. Tondelier, B. Geffroy, O. Jeannin, J. Rault-Berthelot, R. Métivier, C. Poriel, Angew. Chem. Int. Ed. 2015, 54, 1176, b. M. Romain, D. Tondelier, B. Geffroy, O. Jeannin, E. Jacques, J. Rault-Berthelot, C. Poriel, Chem. Eur. J., 2015, 21, 9426, c. S. Thiery, D. Tondelier, C. Declairieux, B. Geffroy, O. Jeannin, R. Métivier, J. Rault-Berthelot, C. Poriel, J. Phys. Chem. C, 2015, 119, 5790.

[11]Y. Li, Z. Wang, X. Li, G. Xie, D. Chen, Y.-F. Wang, C.-C. Lo, J. Peng, Y. Cao, S.-J. Su, Chem. Mater. 2015, 27, 1100.

[12]Q. Zhang, J. Li, K. Shizu, S. Y. Huang, S. Hirata, H. Miyazaki, C. Adachi, J. Am. Chem. Soc. 2012, 134, 14706.

[13]C.-C. Lai, M.-J. Huang, H.-H. Chou, C.-Y. Liao, P. Rajamalli, C.-H. Cheng, Adv. Funct. Mat. 2015, 25, 5548.

[14]M. Romain, D. Tondelier, O. Jeannin, B. Geffroy, J. Rault-Berthelot, C. Poriel, J. Mater. Chem. C 2015, 3, 9701

[15]M. Romain, D. Tondelier, B. Geffroy, A. Shirinskaya, O. Jeannin, J. Rault-Berthelot, C. Poriel, Chem. Commun. 2015, 51, 1313.

[16]G. Méhes, H. Nomura, W. Zhang, T. Nakagawa, C. Adachi, Angew. Chem. Int. Ed. 2012, 51, 11311.

[17]S. Thiery, D. Tondelier, B. Geffroy, O. Jeannin, J. Rault-Berthelot, C. Poriel, Chem. Eur. J. 2016, 22, 10136.

[18]C.-J. Lin, H.-L. Huang, T. Mei-Rurng, C.-H. Cheng, J. Display. Tech. 2009, 5, 236.

[19]F. S. Melkonyan, W. Zhao, M. Drees, N. D. Eastham, M. J. Leonardi, M. R. Butler, Z. Chen, X. Yu, R. P. H. Chang, M. A. Ratner, A. F. Facchetti, T. J. Marks, J. Am. Chem. Soc. 2016, 138, 6944.

[20]D. Hellwinkel, W. Schmid, Chem. Ber. 1980, 113, 358.

[21]H. Jiang, J. Sun, New J. Chem. 2013, 37, 3161.

[22]A. Rodriguez-Serrano, V. Rai-Constapel, M. C. Daza, M. Doerr, C. M. Marian, Phys. Chem. Chem. Phys. 2015, 17, 11350.

[23]E. Baranoff, B. F. E. Curchod, Dalton Trans. 2015, 44, 8318. 


\section{Organic Semi-conductors}

Cyril Poriel," Joëlle Rault-Berthelot," Sébastien Thiery, Olivier Jeannin, Urelle Biapo, Denis Tondelier, Bernard Geffroy

\section{Page - Page}

9H-Quinolino[3,2,1-k]phenothiazine: A new electron-rich fragment for organic electronics

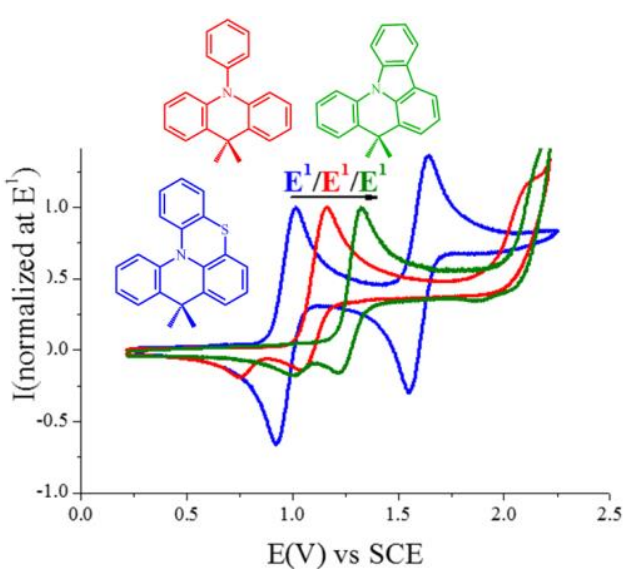

We report a novel electron-rich fragment for organic electronic applications, namely the quinolophenothiazine (QPTZ). The sulphur atom of QPTZ fragment plays a major role in the electronic properties (increasing the HOMO energy level, modulate the spin-orbit coupling...) and leads to highly efficient blue Phosphorescent Organic Light Emitting diode, indicating the strong potential of this new molecular fragment in organic electronics. 